\title{
PROMOTING SLOW TOURISM TO WRESTLE THE CHALLENGES OF SHORTER LENGTH OF TOURIST STAY: IMPLICATIONS FOR SUSTAINABLE TOURISM
}

\author{
Yihalem KEBETE* \\ Bahir Dar University, College of Business and Economics, \\ Department of Tourism and Hotel Management, Ethiopia, e-mail: yihalemkebete19@gmail.com
}

\begin{abstract}
Citation: Kebete, Y. (2021). PROMOTING SLOW TOURISM TO WRESTLE THE CHALLENGES OF SHORTER LENGTH OF TOURIST STAY: IMPLICATIONS FOR SUSTAINABLE TOURISM. GeoJournal of Tourism and Geosites, 39(4spl), 1388-1396. https://doi.org/10.30892/gtg.394spl09-782
\end{abstract}

\begin{abstract}
Slow tourism is an eminent concept that aims to embolden extended tourist stay within a destination. The current study adopts qualitative research approach and extracts data from purposefully selected tourism professionals. The researcher employed both interview and focus group discussion to collect data required for this study. Findings of the current study unfold that slow tourism as a unique approach augments the overall tourism activities, mainly within emerging destinations. Even though slow tourism has received limited attention in Bahir Dar and its surroundings, it is quite substantive to discourage the negative economic, sociocultural and environmental impacts of tourism. However, absence of developed tourism infrastructures and limited understanding of stakeholders restrain the practice and development of slow tourism in the study area. In terms of policy references, the present study suggests that there is a need to develop a practical guideline to inculcate the fundamental concepts related to the practical applications of slow tourism in emerging destinations.
\end{abstract}

Key words: Bahir Dar, emerging destination, slow tourism, slow travel, sustainable tourism

\section{INTRODUCTION}

Slow tourism as a crucial approach is intending to help tourist destinations through improving tourist length of stays and boosting the economic, sociocultural and environmental qualities (Losada and Mota, 2019; Serdane et al., 2020; Szromek et al., 2020). The concept of slow tourism incorporates any travel that discovers new tourism resources in order to enhance tourist experience (Jensen, 2013). On the other hand, the adoption of slow tourism activities would allow visitors to be habituated with wide variety of tourism products (Wilson and Hannam, 2017; Wondirad et al., 2021). Since its origin is from the food industry (Millington, 2011), the theory of slow tourism is intermingled with slow food that enlivens the cultural, economic and environmental aspects of a destination (Clancy, 2017; Wilson and Hannam, 2017). As slow tourism gives much emphasis on providing authentic tourism products, it nurtures the economic development of the local people (Shang et al., 2020). However, as tourist activities in developing destinations lack proper management (Wondirad et al., 2020), it is elusive to carry out slow tourism. That, in turn, partly affects tourist length of stays (Gossling et al., 2018). Pragmatically, the role of slow tourism in deterring the chronic problems of tourist length of stays has not been examined yet in most emerging destinations (Moira et al., 2017). Due to this reason, slow tourism is still pulverized in emerging destinations (Shang et al., 2020). Hence, it has been underlined that little is known about slow tourism due to inadequate research in such field (Wondirad et al., 2021). In a similar vein, the demand side of slow tourism development has been nebulous, mainly in emerging destinations (Oh et al., 2 014). As a reaction to this, the current study seeks to look at how slow tourism is substantive in elongating tourist length of stays and augmenting sustainable tourism. On the other hand, employing qualitative research with in-depth interview received little attention in most slow tourism researches (Wondirad et al., 2021). Subsequently, this study aims to: (1) inspect whether slow tourism is practiced in Bahir Dar City and its environs (2) to probe how slow tourism could improve tourist length of stays, thereby supplementing the sustainable tourism development and (3) explore the major challenges of slow tourism development in the study area.

\section{LITERATURE REVIEW}

\section{Slow tourism in diverse perspectives}

In the setting of developed destinations such as the Netherlands, Australia and USA, slow tourism has been contemplated as one of the most prominent tools in encouraging host and guest interactions (United Nation World Tourism Organization Report, 2017). These matured destinations have realized slow tourism through providing assortment of tourism products for tourists (Zmyślony et al., 2020). Therefore, in developed destinations, advocating slow tourism is instrumental to enhance tourists' length of stays and reinforce sustainable tourism development (Howard, 2012). Given the presence of enormous tourism products, developing destinations such as Thailand, Laos, Cambodia and Vietnam have untapped potential for the development of slow tourism (World Tourism Organization and Organization of American States Report in 2018). Very recently, due to the provision of new tourism products, these destinations are widely preferred by young travellers who need to

\footnotetext{
* Corresponding author
} 
take part in slow tourism activities (Mayer and Knox, 2006; United Nation World Tourism Organization Report in 2019). In the continent of Africa, mainly Kenya and South Africa have strived a lot to introduce multiple slow tourism activities through promoting their own distinctive tourism resources (World Tourism Organization and Organization of American States Report in 2018). As slow tourism considers tourist preferences (Hall, 2006), it is presumed to be a panacea for the convoluted problems in tourist length of stays within a destination (Shang et al., 2020). Paradoxically, the nomenclature of slow tourism in diverse perspective is different (Khan, 2015). Hence, it is comprehended that what is slow in a given destination may not be slow in the context of other destinations (Miele, 2008). As a response to this, Nistoreanu et al. (2011) proposed that slow tourism should at least satisfy two crucial concepts. 1/ duration: slow tourism activities should encourage tourists to spend at least one week within a destination. 2/ product utilization: in order to expand slow tourism, destinations should offer tourist products that are chiefly local based. Practically, if a destination adopts slow tourism approach, tourist length of stays is supposed to be extended. That, in turn, fosters tourist experiences (Jensen, 2013; Szromek and Naramski, 2019).

\section{Supplementing tourist length of stay through slow tourism}

Most importantly, tourists need to stay longer to experience a variety of tourism resources (Jensen, 2013; SteenJacobsen et al., 2018). Hence, tourist length of stays could be enhanced through introducing a range of tourism products (Gossling et al., 2018). That would be vital for developing destinations where poor host-guest interaction has been manifested for long. Thus, adopting the concept of slow tourism is substantive in augmenting tourist length of stays (Sun and Lin, 2018; Wondirad et al., 2021). As tourists often need to experience many trips (Martı ' nez-Garcia and Raya, 2008), slowing down the fast pace of travel is profoundly imperative to enhance tourist length of stays within a destination (Howard, 2012; Sun and Lin, 2018). Since an extended tourist stays has multiple significances, it has to get a prominent consideration among tourism business operators (Yang et al., 2011). Hence, so as to compliment tourist length of stays, tourist service providers should imagine the real time that tourists need to spend through referring tour itineraries that tourists pursue during travel (Wang et al., 2012). On the other hand, tourism business operators could handle their administrative costs and adjust their own promotional strategies (Mart1 ' nez-Garcia and Raya, 2008; Ritchie and Crouch, 2005). A few studies in tourism purported that tourist length of stays is impacted by tourists' demographic characteristics, level of income and price of the tourism products and services (Alegre and Pou, 2006; Barros Pestena and Machado, 2010; Yang et al., 2011). However, the current study emphasized that introducing slow tourism undertakings could be one of the most crucial factors that enrich tourist length of stays. Thus, in tourist areas where shorter visitor stay continues, reducing the fast pace of travel would be viewed as one of the most important remedies for the chronic problem in tourist length of stays (Gossling et al., 2018; Lumsdon and McGrath, 2011; Peypoch et al., 2012; Sun and Lin, 2018). As far as the current study is considered, the link between slow tourism initiatives and tourist length of stays has three scopes. 1/ as slow tourism development is partly improved through giving adequate attention to natural and cultural tourism resources, it encourages many tourists to experience more and stays longer within the study area 2/ slow tourism development is helpful to create proper channel of communication among tourism business operators working in the study region, thereby fostering the tourist experience and enhancing tourist length of stays. 3/building long-term host-guest interaction and satisfying the interests of tourists could be helpful to supplement slow tourism development that will enhance tourist length of stays.

\section{Setting the research context}

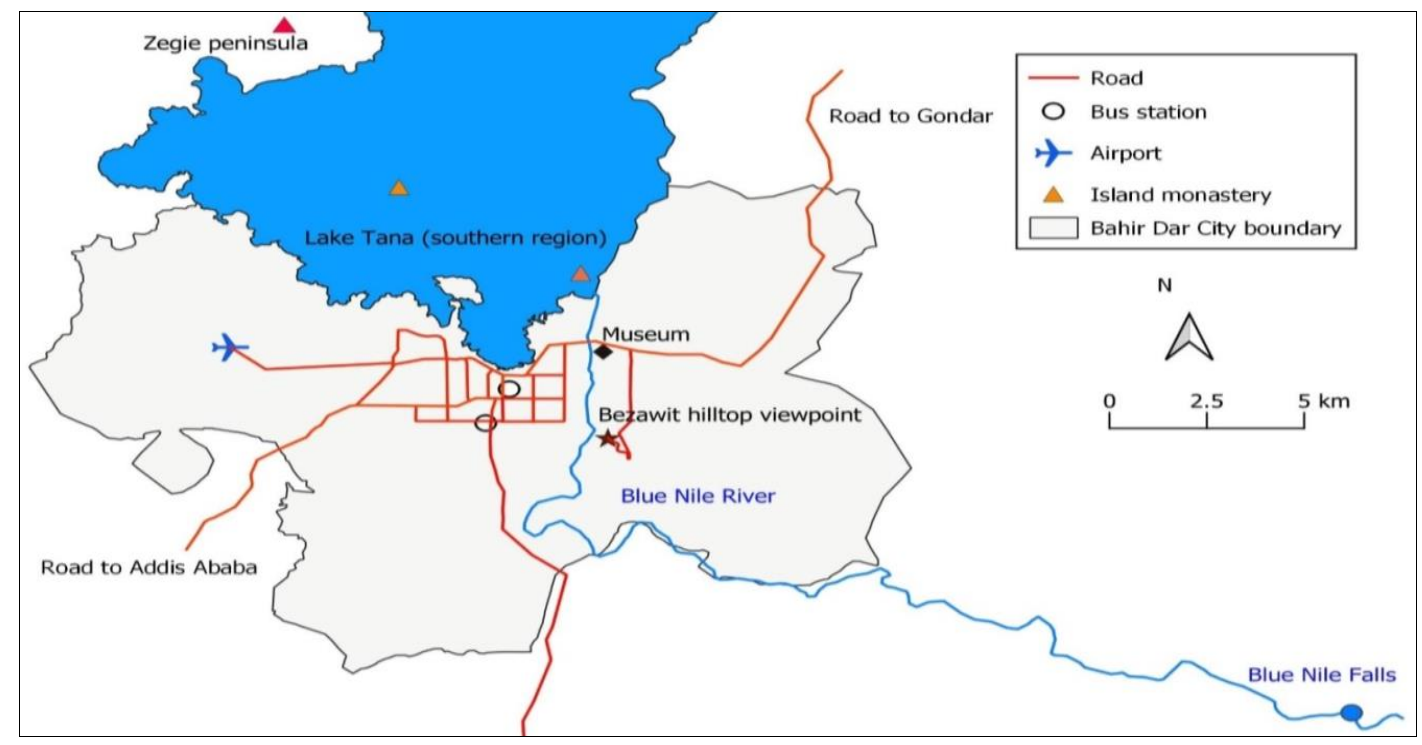

Figure 1. Map of Bahir Dar City and its hinterlands

This study was conducted in Bahir Dar City and its hinterlands. It is located in the North Western Ethiopia. The city is situated about 578km Northwest of Addis Ababa. Bahir Dar City has an elevation of 1840m above sea level. It is the capital city of the Amhara region. Zegie Peninsula Monasteries and Tis Abay/ Blue Nile Fall are the most prominent tourist sites found within the territory of Bahir Dar city administration. As shown in Figure 1, Bahir Dar City is one of the most historical 
part of Ethiopia hosting several manmade and natural attractions. The monastery of Zegie Peninsula, Island Monastries, Bezawit hill top viewpoint, Museum, Lake Tana and the Blue Nile River are the most often visiting places found in Bahir Dar and its hinterlands. Lake Tana, the largest lake of Ethiopia, entices the visitors with its atmosphere of timless spectacle.

\section{RESEARCH METHOD}

Qualitative research method is the preferred approach used in exploring new concepts and issues in the field of tourism and hospitality (Robbins and Cho, 2012). As the current study scrutinizes slow tourism practice and its role in boosting tourist length of stays and sustainable tourism development, a qualitative approach has been pursued. Regarding data collection instruments, studies to be conducted through taking data from professionals often use interview and focus group discussion in order to investigate major concepts and associated problems (Berg, 2007; Lumsdon and McGrath, 2011; Oh et al., 2016). Thus, the present study executed face to face structured and semi-structured interview types and focus group discussion to extract data from research participants.

\section{Sampling and participant recruitment process}

The contemporary studies emphasized that the number of research participants in qualitative studies would be different based on the nature of the problem to be investigated (Waseema, 2017). To mention some studies, Dickinson et al. (2011) has selected eight samples in his study about slow travel and tourism. On the other hand, Lumsdon and McGrath (2011) used twenty-five participants who have been involved in tourism businesses. For the present study, 40 research participants were selected through purposive sampling technique. Data collection was conducted in Bahir Dar City (the capital of Amhara National Regional State, Ethiopia), Tiss Abay (a small town where the Blue Nile Fall is found) and Zegie Peninsula (a home to more than 10 ancient monasteries and found in the Lake Tana region).

Table 1. Demographic profile of research participants

\begin{tabular}{|c|c|c|c|c|c|c|c|}
\hline Lists of participants & Relevance to research & Places & Codes & Age & Sex & Y.E & T.L \\
\hline \multirow{7}{*}{ Academicians } & \multirow{7}{*}{$\begin{array}{l}\text { Academicians are supposed to have deeper } \\
\text { knowledge regarding slow tourism and its role } \\
\text { for tourist length of stay and sustainable } \\
\text { tourism development. }\end{array}$} & \multirow{7}{*}{ Bahir Dar } & $\mathrm{AD}_{1}$ & $20-30$ & $\mathrm{~F}$ & 6 & \multirow{7}{*}{7} \\
\hline & & & $\mathrm{AD}_{2}$ & $31-40$ & $\mathrm{~F}$ & 11 & \\
\hline & & & $\mathrm{AD}_{3}$ & $31-40$ & $\mathrm{M}$ & 11 & \\
\hline & & & $\mathrm{AD}_{4}$ & $20-30$ & $\mathrm{~F}$ & 9 & \\
\hline & & & $\mathrm{AD}_{5}$ & $31-40$ & $\mathrm{M}$ & 12 & \\
\hline & & & $\mathrm{AD}_{6}$ & $31-40$ & $\mathrm{M}$ & 8 & \\
\hline & & & $\mathrm{AD}_{7}$ & $20-30$ & $\mathrm{M}$ & 7 & \\
\hline \multirow{5}{*}{$\begin{array}{l}\text { Tourism business } \\
\text { consultants }\end{array}$} & \multirow{5}{*}{$\begin{array}{l}\text { To the best of the researcher's knowledge, } \\
\text { travel and tourism business consultants have } \\
\text { good understanding with respect to slow } \\
\text { tourism and sustainability issues. }\end{array}$} & \multirow{5}{*}{ Bahir Dar } & $\mathrm{CT}_{1}$ & $41-50$ & $\mathrm{M}$ & 10 & \multirow{5}{*}{5} \\
\hline & & & $\mathrm{CT}_{2}$ & $50+$ & $\mathrm{M}$ & 15 & \\
\hline & & & $\mathrm{CT}_{3}$ & $31-40$ & $\mathrm{~F}$ & 9 & \\
\hline & & & $\mathrm{CT}_{4}$ & $31-40$ & $\mathrm{M}$ & 11 & \\
\hline & & & $\mathrm{CT}_{5}$ & $41-50$ & $\mathrm{~F}$ & 11 & \\
\hline \multirow{4}{*}{ Tour operators } & \multirow{4}{*}{$\begin{array}{l}\text { As tour operators are expected to utilize slow } \\
\text { tourism potentials and curb challenges, the } \\
\text { present study has used data obtained from } \\
\text { them. }\end{array}$} & \multirow{4}{*}{ Bahir Dar } & $\mathrm{TR}_{1}$ & $20-30$ & $\mathrm{M}$ & 6 & \multirow{4}{*}{4} \\
\hline & & & $\mathrm{TR}_{2}$ & $31-40$ & $\mathrm{~F}$ & 12 & \\
\hline & & & $\mathrm{TR}_{3}$ & $41-50$ & $\mathrm{M}$ & 13 & \\
\hline & & & $\mathrm{TR}_{4}$ & $31-40$ & $\mathrm{~F}$ & 11 & \\
\hline \multirow{6}{*}{$\begin{array}{l}\text { Destination } \\
\text { management experts }\end{array}$} & \multirow{6}{*}{$\begin{array}{l}\text { Problems with respect to tourist length of stay } \\
\text { and slow tourism are the concern of destination } \\
\text { management experts. Hence, it is crucial to } \\
\text { involve them in this study. }\end{array}$} & \multirow{4}{*}{ Zegie } & $\mathrm{DM}_{1}$ & $50+$ & $\mathrm{M}$ & 17 & \multirow{4}{*}{4} \\
\hline & & & $\mathrm{DM}_{2}$ & $41-50$ & $\mathrm{M}$ & 14 & \\
\hline & & & $\mathrm{DM}_{3}$ & $31-40$ & $\mathrm{~F}$ & 12 & \\
\hline & & & $\mathrm{DM}_{4}$ & $31-40$ & $\mathrm{~F}$ & 15 & \\
\hline & & \multirow{2}{*}{ Tiss Abay } & $\mathrm{DM}_{5}$ & $50+$ & $\mathrm{M}$ & 17 & \multirow{2}{*}{2} \\
\hline & & & $\mathrm{DM}_{6}$ & $20-30$ & $\mathrm{~F}$ & 7 & \\
\hline \multirow{6}{*}{ Tour guides } & \multirow{6}{*}{$\begin{array}{l}\text { As tour guides have an extensive contact with } \\
\text { tourists, they are supposed to know some } \\
\text { crucial factors that determine tourist length of } \\
\text { stay. }\end{array}$} & \multirow{3}{*}{ Zegie } & $\mathrm{TG}_{1}$ & $20-30$ & $\mathrm{M}$ & 7 & \multirow{3}{*}{3} \\
\hline & & & $\mathrm{TG}_{2}$ & $20-30$ & $\mathrm{M}$ & 9 & \\
\hline & & & $\mathrm{TG}_{3}$ & $31-40$ & $\mathrm{~F}$ & 12 & \\
\hline & & \multirow{3}{*}{ Tiss Abay } & $\mathrm{TG}_{4}$ & $31-40$ & $\mathrm{~F}$ & 10 & \multirow{3}{*}{3} \\
\hline & & & $\mathrm{TG}_{5}$ & $20-30$ & $\mathrm{M}$ & 9 & \\
\hline & & & $\mathrm{TG}_{6}$ & $31-40$ & $\mathrm{M}$ & 11 & \\
\hline \multirow{12}{*}{$\begin{array}{l}\text { Focus group } \\
\text { participants }\end{array}$} & & & $\mathrm{FGP}_{1}$ & $31-40$ & $\mathrm{M}$ & 13 & \\
\hline & & Bahir Dar & $\mathrm{FGP}_{2}$ & $20-30$ & $\mathrm{~F}$ & 7 & 4 \\
\hline & & Bahır Dar & $\mathrm{FGP}_{3}$ & $50+$ & $\mathrm{M}$ & 16 & 4 \\
\hline & & & $\mathrm{FGP}_{4}$ & $31-40$ & $\mathrm{~F}$ & 10 & \\
\hline & & & $\mathrm{FGP}_{5}$ & $20-30$ & $\mathrm{~F}$ & 6 & \\
\hline & & Zeqie & $\mathrm{FGP}_{6}$ & $41-50$ & $\mathrm{M}$ & 18 & 4 \\
\hline & & Legie & $\mathrm{FGP}_{7}$ & $31-40$ & $\mathrm{~F}$ & 13 & 4 \\
\hline & & & $\mathrm{FGP}_{8}$ & $41-50$ & $\mathrm{M}$ & 15 & \\
\hline & & & $\mathrm{FGP}_{9}$ & $20-30$ & $\mathrm{M}$ & 7 & \\
\hline & & Tiss Abay & $\mathrm{FGP}_{10}$ & $31-40$ & $\mathrm{~F}$ & 13 & 4 \\
\hline & & & $\mathrm{FGP}_{11}$ & $50+$ & M & 19 & 4 \\
\hline & & & $\mathrm{FGP}_{12}$ & $20-30$ & $\mathrm{~F}$ & 7 & \\
\hline
\end{tabular}

As evidences obtained from Amhara National Regional State Culture and Tourism Bureau (2019) divulges, most experienced tour guides and destination management experts have been working in Zegie and Tis Abay. Thus, destination management experts and tour guides were selected from Tiss Abay and Zegie whereas academicians, tourism 
and hospitality business consultants and tour operators were selected from Bahir Dar City (Table 1). Interviews were conducted in three phases. Phase one has been done in Bahir Dar for two months. Phase two has been conducted in Zegie for six consecutive weeks and phase three has been undertaken in Tiss Abay for four weeks. In all the three phases, data saturation has been considered while conducting interview and checking whether to proceed to the next participant (Kebete and Wondirad, 2019). On the other hand, to triangulate data obtained through interviews, the researcher conducted focus group discussion in Bahir Dar City. Hence, purposefully selected experienced tourism professionals working in Zegie (4), Tiss Abay (4) and Bahir Dar (4) have partaken in the discussion.

\section{DATA ANALYSIS PROCESS}

Since the researcher extracted data from participants through using semi-structured interview and focus group discussion guides, the following four steps have been pursued to record and analyze the data: First, the researcher has conducted interview and undertaken audio taping. Second, transcribe data and arrange it carefully. This step shows representation of noticeable and visual data into written form (Gibbs, 2002). Thus, it is an interpretive process which is considered as the first step in analyzing qualitative data (Berg, 2007). Third, code the data and produce themes: in this phase the researcher was looking for similar words or phrases mentioned by the interviewees and focus group discussants to generate categories/themes (Pink, 2008; Wondirad et al., 2021). Fourth, the researcher made comprehensive statement from the themes and interpreted the result in light of existing literatures in the field of slow and sustainable tourism studies. Overall, the present study has followed the techniques of thematic analysis.

\section{RESULTS AND DISCUSSION}

The demographic profile of respondents shows that $55 \%$ of participants are male, while the rest $45 \%$ are female. $43 \%$ of participants have professional experience covering from six to ten years, whereas $45 \%$ of them have eleven to fifteen years of experience. $12 \%$ of participants had experience from sixteen to twenty years. As far as age is concerned, $43 \%$ of participants belong to the age category of 31-40 and 30\% of them belong to the 20-30 age categories. On the other hand, 15\% of respondents were found between the age of 41 and 50 whereas the 50+ category consists of only $12 \%$ of the entire participants.

\section{Slow tourism and its applicability in Bahir Dar and its surroundings}

It has been realized that Bahir Dar and its environs has not been fully working on slow tourism for long (Wondirad et al., 2021). This is due to the fact that tour operators, travel agents and tour guides operating in the study area did not copiously apprehend the concept of slow tourism and its contribution in extending tourist length of stays (Amhara National Regional State Culture and Tourism Bureau, 2019). This is further strengthened by what research participants stated below:

Tour operators, travel agents and tour guides working in the study area were not able to show which potential tourism activities stimulate slow tourism. Due to this circumstance, many visitors could not have deeper experience during their stay within Bahir Dar City and its environs. It is also understood that limited slow tourism practices in the study region partly made tourist length of stays minimal $\left(\mathrm{TR}_{4}\right.$, December 2020). As far as I know, tour and travel companies functioning in the study area have limited understanding with respect to slow tourism. As a result of this, slow tourism activities are executed to a little extent in Bahir Dar City and its surroundings. Practically, there is almost no propensity to develop slow tourism in the study area. Hence, it is supportive to introduce a range of tourist activities in order to undertake slow tourism activities in the study area $\left(\mathrm{DM}_{3}\right.$, October, 2020). In line with this, Lumsdon and McGrath (2011) and Waseema (2017) pointed out that slow tourism as a distinctive approach embroils wide variety of tourist activities with slow movement to acquire in-depth experience and ensure longer tourist stay. On the other hand, pertaining to the unique features of slow tourism, a tourism and hospitality business consultant mentioned that: Based on my expertise in slow tourism, there is a tendency to practice the whole things indigenous. For example, cultural restaurants should buy food ingredients from the local market rather than using imported food raw materials. That, in turn, encourages local food suppliers to produce larger quantities of ingredients. In addition to this, in the study area, tourists often tend to use the local modes of transportation to travel from one tourist site to the other. Thus, one inimitable feature of slow tourism is its strong attachment with local communities' resource. As slow tourists are local lovers, they are encouraged to taste something exceptional without distracting local resources within the study area. Finally, for the sake of ensuring slow tourism development, Bahir Dar and its environs would better promote tourist activities that are predominantly indigenous ( $\mathrm{CT}_{4}$, May 2019).

This result of the present study corresponds with the finding of Szromek and Naramski (2019) who accentuated that slow tourism primarily utilizes local resources and mainly emphasis on the exploration and provision of products that are not extensively available elsewhere. Research participants were also asked: do you think that slow tourism is a solution for the fast pace of travel and tourism activities in Bahir Dar City and its vicinity? How? Yes, on average, tourists stay in Bahir Dar for not more than two nights. They visit popular attractions (Blue Nile Falls and Zegie Peninsula Monasteries and the Lake Tana region) in one and half day. As such, tourists' movement within these prominent attractions is conducted in a hurry, and they do not have enough time to explore and experience other attractions. This is especially true for tourists that come in package tours and travel in a fixed schedule with little chance to interact with the local people. As the current tourism development in Bahir Dar and its surroundings suffers from what is called the 'tourist bubble', evolving slow tourism activities could be part of the solution $\left(\mathrm{AD}_{1}\right.$, September 2020). Yes, it could be a solution. So far, tourists that have been visiting Bahir Dar and its surroundings travel rushing, and they don't learn more and don't spend a lot. Thus, slow tourism would be a panacea for the fast pace of travel in the study area (FGP 7 , May 2019). In my perception, as Bahir Dar and its hinterlands attract tourists that acquire in-depth experience and intrinsic learning, slow tourism contributes a lot in elongating tourist length of stays $\left(\mathrm{TR}_{3}\right.$, September 2020$)$. Slow tourism should be considered as an eminent strategy in 
reducing fast movement of visitors (Sun and Lin, 2018). Therefore, it has to get a great emphasis in the contemporary

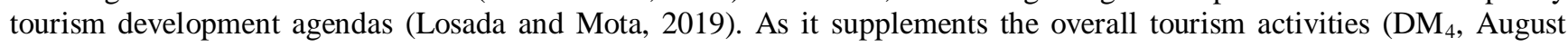
2020), slow tourism extends tourists length of stays within the study area (Wondirad et al., 2021). Hence, implementing slow tourism would act as an antidote for the problem in tourist length of stays in most emerging tourist destinations such as Bahir Dar and its vicinities $\left(\mathrm{TA}_{3}\right.$, May 2020). More importantly, slow tourism initiatives meaningfully enhance sustainable tourism development in tourist receiving areas across the globe (Shang et al., 2020; Szromek and Naramski, 2019).

\section{Slow tourism as a driver of sustainable tourism development}

Since the practice of slow tourism intensifies much contact between tourists and local communities (Dickinson and Peeters, 2014), it would be helpful to augment the sustainable tourism development approaches (Lin, 2017). As Bahir Dar and its environs include people with diverse culture, adopting slow tourism activities advance the socio-cultural, economic and environmental aspects of sustainable tourism (Amhara National Regional State Culture and Tourism Bureau, 2019). Regarding slow tourism and its role in strengthening the socio-cultural sustainability of the study area, a tourism and hospitality business consultant mentioned that: As far as my experience is concerned, slow tourism enables visitors to obtain deep understanding about the social and cultural elements of the study area. Hence, it is substantive to safeguard local authentic culture, heritage and history of the study area. Since Bahir Dar and its environs embrace eccentric cultural tourism resources, slow tourism upholds sustainable tourism development. On the other hand, as slow tourism revitalize careful usage of cultural resources; it plays its part in enlarging tourist length of stays and buttressing the socio-cultural sides of sustainable tourism $\left(\mathrm{CT}_{4}\right.$, September 2020). This result of the present study confirms what Nilsson et al. (2011) accentuated as slow tourism struts the socio-cultural dimension of sustainable tourism through maintaining religious and traditional values. Distinctly, ethical aspects that do not harm the local people need to be contemplated as an important element in slow tourism (Pecsek, 2016). Moreover, slow tourism appreciates long-term contact between the host and the guest within tourist destinations (Shang et al., 2020). In this juncture, slow tourism practices allow tourists to have strong interaction with the local community and learn more about local culture and the environment $\left(\mathrm{DM}_{2}\right.$, March 2020). In relation to environmental issues, slow tourism activities do not often damage the natural balance of tourist destinations (Shang et al., 2020). Therefore, in all aspects, slow tourism needs to be performed via maintaining the environmental settings of the study area as stated by a research participant below:

As you may also know, slow tourism would enrich tourism activities that improve environmental qualities. I want to underscore that the development of tourism in Bahir Dar City should stimulate slow tourism activities in order to encourage environmental conservation and preservation undertakings. Thus, slow tourism approach is quite prominent in ensuring sustainable tourism development in the study area $\left(\mathrm{CT}_{3}\right.$, February 2020). Moreover, performing slow tourism activities enrich the environmental sustainability of tourism through discouraging ecological degradation and reducing the use of chemicals for waste management (Lenzen et al., 2018; Shang et al., 2020). On the other hand, slow tourism considerately advances the duty of tourists in combating environmental pollution and augmenting careful utilization of tourism resources (Valls et al., 2019; Widz and Brzezińska-Wójcik, 2020). Regarding the interest of slow tourists towards protecting the environment from damage, a tour guide working in the study area pointed out that: Slow tourists are presumed to be approachable to the natural and cultural resources of the study area. Slow tourists who are interested in culture must be friendly to the cultural environment. On the other hand, slow tourists that are concerned for nature must be careful to the natural environment. Hence, slow tourism in the study area needs to encompass a responsible travel to the natural and cultural environment $\left(\mathrm{TG}_{2}, \mathrm{May}_{2020) \text {. }}\right.$

Practically, slow tourism embraces ecological sustainability in it (Gunesch, 2017; Pecsek, 2016). In light of that, introducing environmentally friendly tourism activities with comfortable travel are fundamental for the development of slow tourism (Jernsand et al., 2015; Shang et al., 2020). Thus, enabling tourists to stay longer and enjoy the lesser known tourism products would allow tourist destinations to rejuvenate extensively visited and environmentally degraded sites (Alegre et al., 2011). Even though ecological sustainability issue is part and parcel of slow tourism development, it has received little emphasis in Bahir Dar and its environs (Amhara National Regional State Culture and Tourism Bureau, 2019). As a result, there is almost no attention paid for the prudent utilization of the natural and cultural resources in order

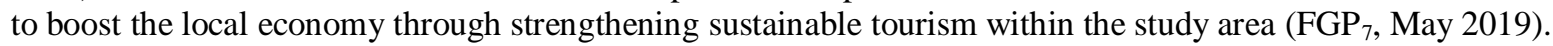

The link between slow tourism and local economic development mainly contingent on communities' resource and thus it is less costly than other tourism activities emphasizing on imported products (Wondirad et al., 2021). So long as slow tourism products are local based, tourists are supposed to pay fair price for the products and services (Oh et al., 2016). Money to be generated from slow tourism activities would be utilized within the study area in order to support the local economy as the following statement unfolds: The adoption of slow tourism in Bahir Dar and its surroundings encourages local entrepreneurship. That is substantive to create job opportunities for the youth and enlarge tax revenue for the government. That, in turn, underpins the infrastructural developments within and around Bahir Dar City $\left(\mathrm{AD}_{3}\right.$, June 2020). Therefore, local communities could take full advantage of slow tourism in terms of creating a greater level of quality experience (Fullargar et al., 2012; Valls et al., 2019). This is further strengthened by a research participant as underscored below: Slow tourism enhances a viable and long-term economic operation through providing socioeconomic benefits for all stakeholders including local communities within the study area. It appreciates the creation of stable income and social services designed for host communities, thereby contributing to the poverty alleviation initiatives of Bahir Dar City and its surroundings ( $\mathrm{DM}_{1}$, August 2020). It has been pointed out that if slow tourism received strong focus in the sustainable tourism development programs, unemployment and poverty related problems would be slackening in the study region $\left(\mathrm{TR}_{3}\right.$, August, 2020). Thus, from the economic aspect, slow tourism and sustainable tourism upsurge tourist expenditure within Bahir Dar City and its surroundings (Wondirad et al., 2021). 
Furthermore, after reviewing extant literatures in the field of slow tourism and sustainable tourism and analyzing data obtained from research participants, the researcher proposed slow tourism framework that interconnects slow tourism, sustainable tourism and tourist length of stays within tourist destinations. Implementing this framework is ideal for the study area and other similar destinations to improve sustainable tourism development through slow tourism.

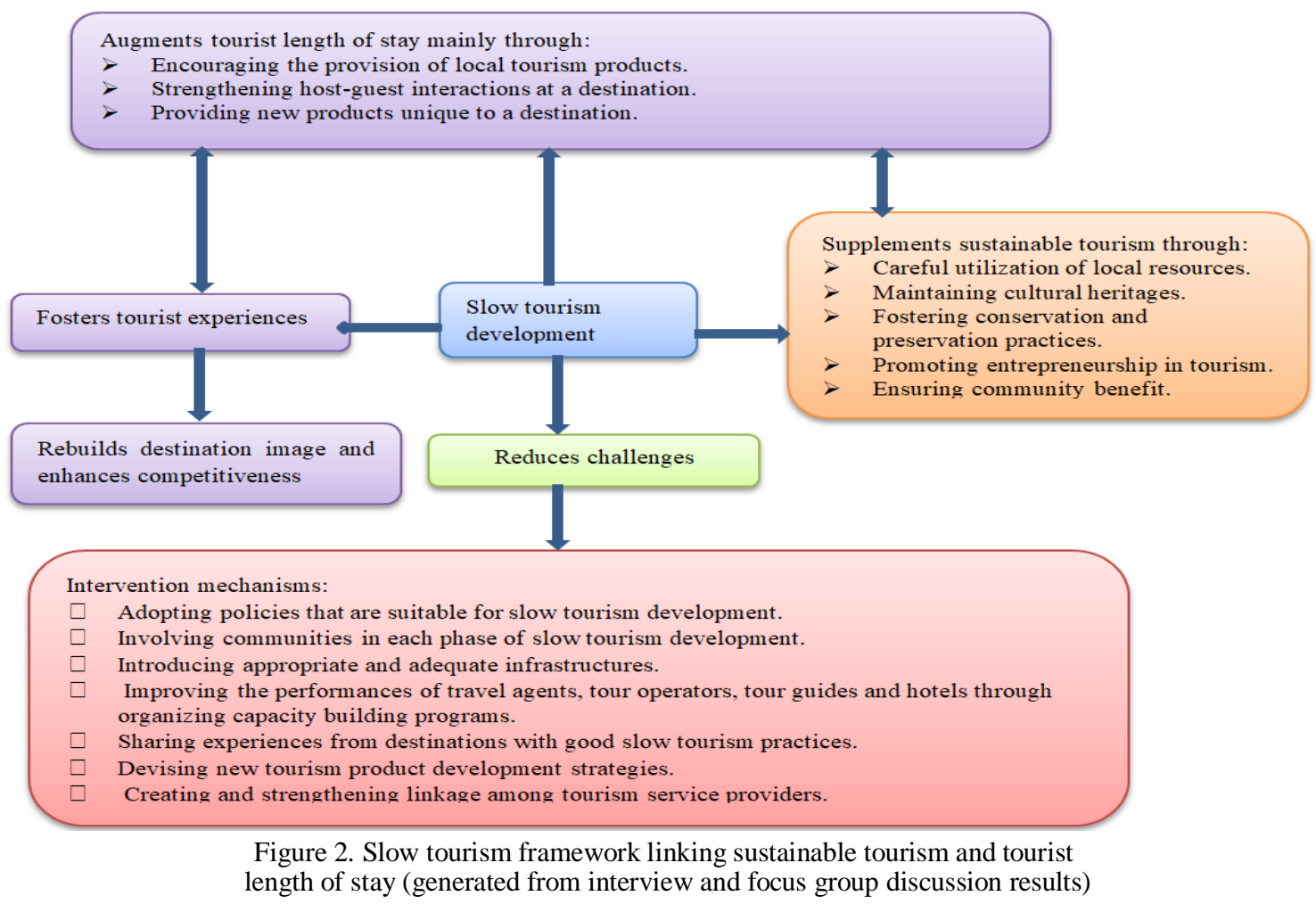

As illustrated in Figure 2, the development of slow tourism steps up sustainable tourism as it facilitates the prudent utilization of natural and cultural heritages and boosts the social, economic and environmental qualities of tourist destinations. The implementation of slow tourism in tourist destinations is profoundly paramount in improving tourist length of stays through encouraging the provision of locally owned tourist products and increasing the performances of tourism business operators in order to meet the interests of the tourists. As shown in Figure 2, the conceptual framework of slow tourism comprises four major components. 1/ tourist experiences: as slow tourism desires the provision of multiple tourist products, it satisfies the interests of tourists, thereby enhancing the tourist experience within the study area (Jensen, 2013). 2/ tourist length of stays: since slow tourism adds tourist experiences and satisfies tourists' demand, it has a great role in enlarging tourist length of stays in Bahir Dar City and its vicinities (Sun and Lin, 2018). 3/ destination image and competitiveness: as long as slow tourism braces tourist experiences and length of stays, it improves destination image and competitiveness. 4/ sustainable tourism: the ultimate goal of slow tourism is to ensure sustainable tourism development through improving tourist length of stays (Shang et al., 2020). On the other hand, applying intervention mechanisms would be instrumental to reduce the challenges that slow tourism confronted in emerging destinations including Bahir Dar City and its hinterlands.

\section{Challenges of slow tourism development in the study area}

Although slow tourism contributes its part in expanding sustainable tourism development, it encounters many challenges, mainly in emerging tourist destinations (Pecsek, 2016). In the context of Bahir Dar and its surroundings, the absence of adequate tourist infrastructures hold down the development of slow tourism (focus group discussion, May 2019). For instance, there has not been any seat designed for tourists who walk on foot within Zegie and around the Blue Nile Fall $\left(\mathrm{TR}_{1}\right.$, June 2019). Because of this reason, aged and physically disabled visitors were not able to go further in order to visit more within Zegie Peninsula Monasteries (Kebete and Wondirad, 2019). This circumstance dissuades the development of slow tourism in the study area as a focus group participant mentioned below:

Even though slow tourism activities entail plentiful tourism infrastructures, the provision of inadequate facilities do not enable visitors to stay longer within the study area. This condition hampers tourist activities, thereby reducing the tourist experiences. That restricts the development of slow tourism (FGP 5 , May 2019).

In line with this, Murphy et al. (2000) and Dupeyras and MacCallum (2013) pointed out that in slow tourism, tourists expect abundant facilitates within a destination equivalent to what they desire to enjoy. However, absence of hotel facilities

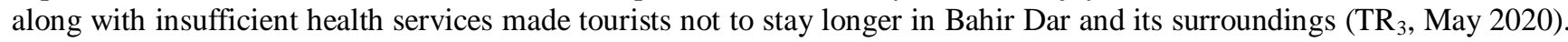
This problem is burgeoning, chiefly in Zegie and around the Blue Nile Falls as the following quote unveils: As far as I know, though the study area is endowed with tremendous organic food items, there were no organized traditional restaurants that provide local cuisines for tourists. For example, on February, 19 2020, I visited Zegie Peninsula Monasteries. During that time, I found no restaurant providing food services, despite the presence of ample agricultural products. On the other hand, 
there were no local transport facilities that support visitors to enter into each part of Zegie Peninsula Monasteries. This circumstance impedes tourist experience, thereby lessening the tourist length of stays in the study area. Therefore, promoting locally owned tourist facilities would be helpful to curb problems in tourist length of stays, thereby escalating the development of slow tourism in one hand and sustainable tourism on the other hand $\left(\mathrm{CT}_{5}\right.$, June 2020). Moreover, as far as the study area is concerned, one of the missed concepts is about promotional activities related to slow tourism as it usually hinges on the same values and principles that are not vital for searching the big pictures of tourism activities ( $\mathrm{AD}_{1}$, November 2020). No matter how rich in spectacular tourism resources the study area is, marketing and promotional activities have been done without contemplating the interests of the tourist and the local community (Amhara National Regional State Culture and Tourism Bureau, 2017). This sense is against to the notion of slow travel as it respects and ensures the benefits of both the local people and the tourist (Dickinson and Lumsdon, 2010; Egresi, 2018; Pink, 2008). Practically, absence of coordination among tourism stakeholders in the study region overwhelms the development of slow tourism. Hence, tour operators, travel agents, tour guides, hotels, transportation service providing institutions and government should work in cohabitation in order to improve tourist length of stays and enlarge sustainable tourism development in the study area.

\section{CONCLUSION AND IMPLICATIONS}

In the contemporary tourism destinations, tourist experience is influenced by the practice and development of slow tourism initiatives (Caffyn, 2012; Lenzen et al., 2018; Waseema, 2017). Findings of the current study unfold that consistent provision of authentic tourism products would be helpful for improving slow tourism activities in the study area. Even though its scope is wide, the current study discussed slow tourism in relation to seven fundamental dimensions. 1/ Travel: slow tourism embraces slow travel to tourist destination where tourism resources are extensively available (Sun and Lin, 2018). Regarding this, a destination management representative underscored that there is an immediate need to interconnect each tourism resource with slow tourism in the study area $\left(\mathrm{DM}_{2}\right.$, June 2020). On the other hand, travel as one of the most crucial components of slow tourism has to be guided by well-planned itineraries (Dickinson et al., 2011; Sun and Lin, 2018). 2/ Authenticity in culture: as slow tourists seek to experience something unique (Jensen, 2013; Meng and Choi,

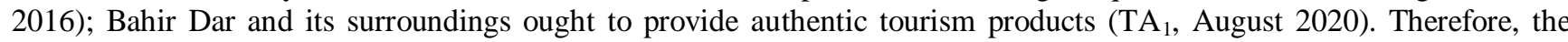
provision of genuine tourism product would enhance the development of slow tourism in tourist destinations (Egresi, 2018; Nilsson et al., 2011). (3) Natural resources: since the study area is rich in natural resources (Amhara National Regional State Culture and Tourism Bureau, 2019), there is a great opportunity for slow tourists to take part in many tourism related activities. As most tourism activities are undertaken in the natural environment (Wondirad et al., 2020), slow tourism has been chiefly contingent on natural resources (Andrews, 2006; Lenzen et al., 2018; Szromek and Naramski, 2019). (4) Tourist experiences: since slow tourism links tourist demand with tourism supplies (Shang et al., 2019), the study area has to properly utilize its tourism resources and examine whether those resources indulge tourists' demand (AD ${ }_{2}$, June 2020). As such, in order to promote slow tourism, tourism business operators should commensurate the supply of tourism products with the immediate demand of the tourist (Warren, 2011). (5) Stay: slow tourism activities encourage tourists to stay longer as peculiar tourism products are frequently provided within emerging destinations like Bahir Dar and its surroundings (Meng and Choi, 2016; Miele, 2008). (6) Learn: slow tourism provides chances for guests to learn more and create strong interaction with the local people. (7) Provision of multiple tourist products: As Bahir Dar and its environs seek to advance slow tourism activities, several tourism products are likely to be available for tourists (Yurtseven and Kaya, 2011). However, inadequate road and transportation services, poor health and telecommunication facilities along with insufficient hotel services curtail the development of slow tourism in the study area. Thus, both the government and the private sector should work cooperatively to develop infrastructures that are substantive for slow tourism initiatives.

\section{Theoretical implications}

Previous studies in slow tourism have been done through involving tourists from the demand side (Losada and Mota, 2019). Hence, the concept of slow tourism has been associated with tourist behaviors and perceptions (Lin, 2017). However, the current study argues that the adoption and practice of slow tourism would partly be influenced by the tourist destination's overall infrastructural development. The findings of this study unravel that the provision of local tourism products would act as a springboard in promoting slow tourism. This study has identified the fundamental components of slow tourism such as product uniqueness, ecological friendly activities, extensive host-guest interaction, longer tourist stay and less travel. On the other hand, the present study proposed a comprehensive slow tourism framework that integrates the concept of slow tourism with tourist length of stays and sustainable tourism in tourist destinations.

\section{Practical implications}

Adopting the concept of slow tourism in tourist destinations advocates the development of tourism (Moi ra et al., 2017). Hence, the practical implication of the present study is discussed in relation to each tourism stakeholder. Primarily, local communities as owners of tourism resources would get substantial benefits if slow tourism activities are executed. Slow tourism enables local communities to promote their own culture, history, heritage and natural resources. On the other hand, improving slow tourism activities would be profoundly obtrusive for tourism business operators to enhance their performances. When tourists stay longer within a destination, tour operators, travel agents, tour guides, hotels and local transportation service providers could sale more tourism products. Thus, practically, adopting the paradigm of slow tourism enables destinations to generate much amount of income from the visitor economy (Losada and Mota, 2019). Moreover, policymakers could use the findings of the current study as a reference in order to devise sustainable tourism related 
policies. In terms of policy, this study recommends as there is an immediate need to make all stakeholders working together for the proper implementation of slow tourism in emerging destinations where tourist length of stay is short. It could also be helpful to tourism and hospitality business consultants and academicians to get an in-depth understanding with respect to slow tourism and widen their knowledge. Overall, as slow tourism supports sustainable tourism development, tourism stakeholders should do a concrete work to encourage the sociocultural, economic and environmental sustainability agendas and discourage the negative impacts of tourism within a destination (Knox, 2005).

\section{Limitation and future research directions}

Since this study was conducted through employing qualitative research approach, it has been a challenge for the researcher to check the validity of data. However, the researcher used structured and semi-structured interview along with focus group discussion to triangulate data obtained from research participants. Thus, future studies in the area of slow tourism would better employ mixed research approach to obtain wide-ranging results.

\section{Acknowledgement}

The author is grateful to Assistant Professor Tadese Bekele and Mr. Negese Teshager for editing the language of the manuscript. The author also has a great gratitude and respect to all research participants who delivered appropriate data required for this study.

\section{REFERENCES}

Alegre, J., \& Pou, L. (2006). The length of stay in demand for tourism. Tourism Management, 27(2006), 1343-1355. https:// doi.org/10.1016/j.tourman.2005.06.012

Alegre, J., Mateo, S., \& Pou, L. (2011). A latent class approach to tourists' length of stay. Tourism Management, 32 (3), 555-63. https:// doi.org/10.1016/j.tourman.2010.05.003

Andrews, C. (2006). Slow is beautiful: New visions of community, leisure and Joie De Vivre Canada. New Society Publishers. https:// newsociety.com/products/9781550924145

Barros Pestena, C.P., \& Machado, L.P. (2010). The length of stay in tourism. Annals of Tourism Research. 37 (3), 629-706. https:// doi.org/10.1016/j.annals.2009.12.005

Berg, B.L. (2007). Qualitative methods for the social sciences (6th edn). Pearson Education Inc. https://www.academia.edu/1823730/Qualitative

Caffyn, A. (2012). Advocating and implementing slow tourism. Tourism Recreation Research, 37(1), 77-80. https://www. tandfonline.com/doi/abs/10.1080/02508281.2012.11081690

Clancy, M. (2017). Slow tourism, food and cities. Pace and the search for the "good life". London, Routledge. https://doi.org/ $10.4324 / 9781315686714$

Dickinson, J.E., Lumsdon, L.M., \& Robbins, D. (2011). Slow travel: Issues for tourism and climate change. Journal of Sustainable Tourism, 19(3), 281-300. https://www.academia.edu/914729

Dickinson, J.E., \& Peeters, P. (2014). Time, tourism consumption and sustainable development. International Journal of Tourism Research, 16 (1), 11-21. https://doi.org/10.1002/jtr.1893

Dupeyras, A., \& MacCallum, N. (2013). Indicators for Measuring Competitiveness in Tourism: A Guidance Document. OECD Tourism Papers, 2013/02, OECD Publishing. https://doi.org/10.1787/23071672

Egresi, I.O. (2018). Residents' attitudes to tourists visiting their mosques: A case study from Istanbul, Turkey. Journal of Tourism and Cultural Change, 16(1), 1-21. https://doi.org/10.1080/14766825.2016.1192182

Fullargar, S., Markwell, K., \& Wilson, E. (2012). Slow Tourism: Experiences and Mobilities. Channel View Publications, Bristol.15-26. https://www.academia.edu/1616206/Fullagar_S

Gibbs, G.R. (2002). Qualitative data analysis: Explorations with NVivo. Buckingham: Open University Press. 1-257. https://pure. hud.ac.uk/en/publications/qualitative

Gossling, S., Scott, D., \& Hall, C.M. (2018). Global trends in length of stay: Implications for destination management and climate change. Journal of Sustainable Tourism, 26(12), 2087-2101. https://doi.org/10.1080/09669582.2018.1529771

Gunesch, K. (2017). The ecological and social power of slow tourism for sensitive yet profitable environmental sustainability: international insights for airline and business travel from intercultural student and spiritual stakeholders. Review of Socio-Economic Perspectives, 2(1), 125-138. https://pure.buas.nl/en/publications/slow-tourism

Hall, C.M. (2006). Introduction: Culinary tourism and regional development: from slow food to slow tourism. Tourism Review International, 9(4), 303-305. https://doi.org/10.3727/154427206776330580

Howard, C. (2012). Speeding up and slowing down: Pilgrimage and slow travel through time. In slow tourism: Experiences and Mobilities. edited by S. Fullagar, K. Markwell, and E. Wilson. Bristol, UK: Channel View, 11-24. https://www.cabdirect.org/cabdirect/abstract/20123247907

Jensen, M.T. (2013). Book Review: Slow tourism experiences and mobilities. Annals of Leisure Research, 16(4), 377-379. https://www.academia.edu/12163598

Jernsand, E.M., Kraff, H., \& Mossberg, L. (2015). Tourism experience innovation through design. Scandinavian Journal of Hospitality and Tourism, 15 (1), 98-119. https://www.mistraurbanfutures.org/en/publication/

Kebete, Y., \& Wondirad, A. (2019). Visitor management and sustainable destination management nexus in Zegie Peninsula Monasteries, Northern Ethiopia. Journal of Destination Marketing and Management, 13, 83-98. https://doi.org/10.1016/j.jdmm.2019.03.006

Knox, L.P. (2005). Creating ordinary places: Slow cities in a fast world. Journal of Urban Design, 10 (1), $1-11$. https://doi.org/10.1080/13574800500062221

Khan, S. (2015). How slow is slow. Dilemmas of slow tourism. TEAM. Journal of Hospitality and Tourism, 11(1), 39-49. https://www. cabdirect.org/cabdirect/abstract/20163016831

Lenzen, M., Sun, Y.Y., Faturay, F., Ting, Y.P., Geschke, A., \& Malik, A. (2018). The carbon footprint of global tourism. Nature Climate Change, 8(6), 522- 528. https://www.nature.com/articles/s41558-018-0141-x

Lin, L. (2017). Industrial tourists' behavioural intention toward slow travel in Taiwan. Journal of Sustainable Tourism, 25(3), 379-396. https://doi.org/10.1080/09669582.2016.1213848

Losada, N., \& Mota, G. (2019). Slow down, your movie is too fast: Slow tourism representations in the promotional videos of the Douro region (northern Portugal). Journal of Destination Marketing \& Management, 2019 (11), 140-149. https://doi.org/10.1016/j.jdmm.2018.12.007

Lumsdon, L.M., \& McGrath, P. (2011). Developing a conceptual framework for slow travel: a grounded theory approach. Journal of Sustainable Tourism, 19(3), 265-279. https://doi.org/10.1080/09669582.2010.519438 
Mart1'nez-Garcia, E., \& Raya, M. J. (2008). Length of stay for low-cost tourism. Tourism Management, 29(6), 1064-1075. https://doi.org/ 10.1016/j.tourman.2008.02.011

Mayer, H., \& Knox, P. L. (2006). Slow cities: Sustainable places in a fast world. Journal of Urban Affair, 28 (4), $321-334$. https:// doi.org/10.1111/j.1467-9906.2006.00298.x

Meng, B., \& Choi, K. (2016). The role of authenticity in forming slow tourists' intentions: Developing an extended model of goal directed behaviour. Tourism Management, 57, 397-410. https://doi.org/10.1016/j.tourman.2016.07.003

Miele, M. (2008). Citta Slow: Producing slowness against the fast life. Space and Polity, 12 (1), 135-156. https://doi.org/10. 1080/13562570801969572

Millington, K.(2011). The evolution of slow travel. Travel and Tourism Analyst, 4, 1-39. https://www.cabdirect.org/cabdirect/abstract/20113136619

Moira, P., Mylonopoulos, D., \& Kondoudaki, E. (2017). The application of slow movement to tourism: Is slow tourism a new paradigm? Tourism and Leisure Studies, 2(2), 1-10. http://doi.org/10.18848/2470-9336/CGP

Murphy, P., Pritchard, M.P., \& Smith, B. (2000). The destination product and its impact on traveller perceptions. Tourism Management, 21(1), 43-52. https://doi.org/10.1016/S0261-5177(99)00080-1

Nilsson, J.H., Svärd A.C., Widarsson, A., \& Wirell, T. (2011). 'Cittá slow' eco-gastronomic heritage as a tool for destination development. Current Issues in Tourism, 14(4), 373-386. https://doi.org/10.1080/13683500.2010.511709

Nistoreanu, P., Dorobantu, R.M., \& Tuclea, C. (2011). The trilateral relationship ecotourism, sustainable tourism and slow travel among nature in the line with authentic tourism lovers. Journal of Tourism, (11), 34-37. https://www.researchgate.net/profile/Claudia-Tuclea

Oh, H., Assaf, A.G., \& Baloglu, S. (2016). Motivations and goals of slow tourism. Journal of Travel Research, 55(2), $205-219$. http://dx.doi.org/10.1177/0047287514546228

Pecsek, B. (2016). Revitalizing tourism in small regional towns through folklore-driven slow tourism: The example of Matyó land, Hungary. Dos Algarves: A Multidisciplinary e-Journal, 27, 94-119. doi:10.18089/DAMeJ.2016.27.6

Peypoch, N., Randriamboarison, R., Rasoamananjara, F., \& Solonandrasana, B. (2012). The length of stay of tourists in Madagascar. Tourism Management, 33 (5), 1230-1235. https://doi.org/10.1016/j.tourman.2011.11.003

Pink, S. (2008). Sense and sustainability: The case of the slow city movement. Local Environment, 13 (2), 95-106. https://doi.org/ $10.1080 / 13549830701581895$

Ritchie, J.R.B., \& Crouch, G.I. (2005). The competitive destination. A sustainable tourism perspective. Wallingford: CABI. https:// www.scirp.org/(S(oalber55rzwh2u45csg1xrn1

Robbins, D., \& Cho, J. (2012). Slow travellers, who are they, and what motivates them? Paper presented at the BEST EN Think Tank XII: Mobilities and Sustainable Tourism, Vienna.

Serdane, Z., Maccarrone-Eaglen, A., \& Sharifi, S. (2020). Conceptualising slow tourism: a perspective from Latvia. Tourism Recreation Research. 45(3), 337-350. https://doi.org/10.1080/02508281.2020.1726614

Shang, W., Yuan, Q., \& Chen, N. (2020). Examining Structural Relationships among Brand Experience, Existential Authenticity, and Place Attachment in Slow Tourism Destinations, Sustainability, 12(7), 1-23. https://doi.org/10.3390/su12072784

Steen-Jacobsen, J.K., Gossling, S., Dybedal, P., \& Skogheim, T.S. ( 2018). Exploring length of stay: International tourism in southwestern Norway. Journal of Hospitality and Tourism Management, 35, 29-35. https://doi.org/10.1016/j.jhtm.2018.02.003

Sun, Y.Y., \& Lin, Z.W. (2018). Move fast, travel slow: The influence of high-speed rail on tourism in Taiwan. Journal of Sustainable Tourism, 26(3), 433-450. https://doi.org/10.1080/09669582.2017.1359279

Szromek, A.R., Kruczek, Z., \& Walas, B. (2020). The attitude of tourist destination residents towards the effects of over tourism: Kraków case study. Sustainability, 12(1), 1-17. https://doi.org/10.3390/su12010228

Valls, J.F., Mota, L., Vieira, S.C.F., \& Santos, R. (2019). Opportunities for slow tourism in Madeira. Sustainability, 11(17), 1-23. https://doi.org/10.3390/su11174534

Wang, E., Little, B.B., \& DelHomme-Little, B.A. (2012). Factors contributing to tourists' length of stay in Dalian north-eastern China - A survival model analysis. Tourism Management Perspectives, 4, 67-72. https://doi.org/10.1016/j.tmp.2012.03.005

Warren, J.P. (2011). A review of slow travel and tourism. Journal of Sustainable Tourism, 19(7), 916-918. https://doi.org/ $10.1080 / 09669582.2010 .531938$

Waseema, M. (2017). Enhancing destination competitiveness for a sustainable tourism industry: The case of Maldives. OIDA International Journal of Sustainable Development, 10(02), 11-24. https://ssrn.com/abstract=2971661

Widz, M., \& Brzezińska-Wójcik, T. (2020). Assessment of the over tourism phenomenon risk in Tunisia in relation to the tourism area life cycle concept. Sustainability, 12 (5), 1-13. https://doi.org/10.3390/su12052004

Wilson, S., \& Hannam, K. (2017). The frictions of slow tourism mobilities: Conceptualising campervan travel. Annals of Tourism Research, 67, 25-36. https://doi.org/10.1016/j.annals.2017.07.021

Wondirad, A., Tolkach, D., \& King, D. (2019b). Stakeholder collaboration for sustainableecotourism development in the context of developing countries. Tourism Management, 78 (3), 1-21. https://doi.org/10.1016/j.tourman.2019.104024

Wondirad, A., Kebete, Y., \& Li, Y. (2021). Culinary tourism as a driver of regional economic development and socio-cultural revitalization: Evidence from Amhara National Regional State, Ethiopia. Journal of Destination Marketing \& Management, 19(10048), 1-15. https://doi.org/10.1016/j.jdmm.2020.100482

*** Amhara National Regional State Culture and Tourism Bureau. (2017). Report on tourist flow to Amhara national regional state, Bahir Dar. Unpublished document.

*** Amhara National Regional State Culture and Tourism Bureau. (2019). Report on tourist flow to Amhara national regional state, Bahir Dar. Unpublished document.

*** United Nation World Tourism Organization (2017). 2017 is the international year of sustainable tourism for development. https://www.unwto.org/archive/global/press-release/

*** United Nation World Tourism Organization (2019). International tourism highlights. 2019 Edition, Madrid, Spain. https://www. unwto.org/publication/international-tourism-highlights-2019-edition

*** World Tourism Organization and Organization of American States (2018). Tourism and the sustainable development goals: Good practices in the Americas, UNWTO, Madrid. https://doi.org/10.18111/9789284419685

Yang, Y., Wong, K.K.F., \& Zhang, J. (2011). Determinants of length of stay for domestic tourists: Case study of Yixing. Asia Pacific Journal of Tourism Research, 16 (6), 619-633. https://doi.org/10.1080/10941665.2011.610144

Yurtseven, H.R., \& Kaya, O. (2011). Slow tourists: A comparative research based on Citta slow principles. American International Journal of Contemporary Research, 1(2), 91-98. https://www.researchgate.net/publication/264848349

Zmyślony, P., Kowalczyk-Anioł, J., \& Dembińska, M. (2020). Deconstructing the over tourism related social conflicts. Sustainability, 12(4), 1695. https://doi.org/10.3390/su12041695 